Check for updates

Cite this: Mater. Chem. Front. 2020, 4, 3649

Received 10th July 2020 , Accepted 17th September 2020

DOI: 10.1039/d0qm00476f

rsc.li/frontiers-materials

\section{Ultrafast photoinduced electron transfer in conjugated polyelectrolyte-acceptor ion pair complexes $\dagger$}

\author{
Pradeepkumar Jagadesan, (iD) Silvano R. Valandro (iD) and Kirk S. Schanze (iD *
}

\section{Introduction}

Conjugated polyelectrolytes (CPEs) are conjugated polymers featuring ionic side groups. The $\pi$-conjugated backbone in CPEs endows them with efficient light harvesting and light emitting properties, while the ionic sides chains render the polymers water-soluble. ${ }^{1-4}$ Wudl, Heeger and coworkers reported the first conjugated polyelectrolyte in $1987 .{ }^{5}$ Ever since their inception, a wide range of CPEs with diverse backbone structures and side chains have been synthesized for a spectrum of applications such as organic light emitting diodes, ${ }^{6-8}$ organic photovoltaics, ${ }^{9,10}$ drug delivery, ${ }^{11}$ antimicrobials ${ }^{12-15}$ and bioimaging. ${ }^{16}$ Moreover, the remarkable photophysical properties of CPEs such as high fluorescence quantum yields and amplified quenching make them intriguing entities for the detection and sensing of ions, ${ }^{17-19}$ molecules $^{20-22}$ and

Department of Chemistry, University of Texas, San Antonio, One UTSA Circle, San Antonio, TX 78249, USA. E-mail: kirk.schanze@utsa.edu

$\dagger$ Electronic supplementary information (ESI) available. See DOI: 10.1039/ d0qm00476f biomolecules. ${ }^{23-25}$ The strikingly sensitive response in the fluorescence quenching of CPEs towards various analytes at ultralow concentrations is caused by the spatial delocalization and mobility of excitons in the polymer as a result of electron/ energy transfer from the CPE to the quencher. The activity in this area has been propelled since the papers published by Swager and co-workers in $1995,{ }^{26,27}$ in which they presented the first example of amplified quenching of a poly $(p$-phenylene ethynylene) (PPE) conjugated polymer by dimethyl viologen $\left(\mathbf{M V}^{2+}\right)$ with a Stern-Volmer quenching constant $\left(K_{\mathrm{SV}}\right)$ as high as $10^{5} \mathrm{M}^{-1}$. The amplified quenching effect was attributed to an effective photoinduced electron transfer (ET) process, in which a single viologen is sufficient to trap nearly the total exciton energy along one polymer chain. ${ }^{28}$

Whitten, Wudl and co-workers first reported the amplified quenching effect in a water-soluble conjugated polyelectrolyte, in which they demonstrated that the fluorescence of a poly ( $p$-phenylene vinylene) (PPV) polyelectrolyte appended with sulfonate $\left(-\mathrm{SO}_{3}{ }^{-}\right)$functionality was quenched by $\mathbf{M V}^{2+}$ with a $K_{\mathrm{SV}}$ in excess of $10^{7} \mathrm{M}^{-1} \cdot{ }^{29}$ Following this, Tan et al. observed that a PPE-type polyelectrolyte appended with alkyl sulfonate 
groups exhibited amplified quenching upon $\mathbf{M V}^{2+}$ addition in both water and methanol, with $K_{\mathrm{SV}}$ values on the order of $10^{7} \mathrm{M}^{-1} \cdot{ }^{30}$ The enhanced quenching exhibited by CPEs in comparison to Swager's neutral conjugated polymers was attributed to the ultrafast exciton migration along the polymer chain to the quencher as a result of the strong complex formation between the polyelectrolyte and quencher through ion-pairing and hydrophobic interactions.

During the past two decades, significant efforts have been devoted to the design and study of a range of CPEs for chemoand biosensing applications that rely on amplified fluorescence quenching as the predominant signal transduction method. Among the polyelectrolytes, PPE-type CPEs have attracted considerable attention for developing fluorescence-based assays due to their rigid rod structure, high water solubility, fluorescence quantum yield and biocompatibility. ${ }^{31-33}$ The fluorescence quenching of CPEs occurs via one of three pathways, which include energy ${ }^{34,35}$ or electron transfer ${ }^{23,36}$ from the polyelectrolyte to the quencher, or through inter-chain aggregation caused quenching (ACQ). ${ }^{19,37}$ Fluorescence quenching via energy transfer can more often be easily distinguished from the others through the observation of sensitized emission from the quencher. In contrast, fluorescence quenching by an ET pathway involves the generation of the polyelectrolyte cation radical (positive polaron) and the reduced quencher from the excited state of the polymer. Subsequently, the return ET occurs non-radiatively to regenerate the ground state polyelectrolyte and acceptor. Owing to the very short lifetimes $(\sim$ ps time scale) of the polaron states, ultrafast spectroscopy is required for detection and characterization of the intermediate charge transfer (CT) state $\left[\mathbf{C P E}^{\bullet+}, \mathbf{A}^{-}\right]$. To the best of our knowledge, ultrafast transient absorption spectroscopic studies to understand the photoinduced ET process and intermediate CT state of PPE-based CPE and quencher mixtures have not been previously reported. Moreover, understanding the ET mechanism and dynamics and developing strategies to modulate the process are of paramount importance, especially for exploiting CPEs for sensing and photovoltaic applications.

The present investigation seeks to study the mechanism of quenching of a water-soluble PPE-type CPE (CPE) functionalized with alkyl sulfonate $\left(\mathrm{R}_{-} \mathrm{SO}_{3}{ }^{-}\right)$by a set of three cationic electron acceptors $\left(\mathbf{M V}^{2+}, \mathbf{N D I}^{2+}\right.$ and $\mathbf{N M I}^{+}$, Chart 1) with the goal to observe the CT state, its spectral properties, and the dynamics for forward and return ET. For all three CPE-acceptor ion-pair complexes, the absorption bands were substantially red-shifted and their intensities are comparable to the primary absorption of CPE. Addition of $\mathbf{N D I}^{2+}$ and $\mathbf{N M I}^{+}$to $\mathbf{C P E}$ resulted in amplified fluorescence quenching with $K_{\mathrm{SV}} \sim 10^{7} \mathrm{M}^{-1}$. Picosecond transient absorption (TA) spectroscopy of the $\mathbf{C P E} / \mathbf{M V}^{2+}$ complex in water revealed the existence of the $\mathbf{C P E}$ cation radical $\left(\mathbf{C P E}^{\bullet+}\right)$ state. Moreover, the observation of the absorption of reduced $\mathbf{N D I}^{2+}$ in the TA measurements of the CPE $/ \mathrm{NDI}^{2+}$ complex confirms the photoinduced ET process between $\mathbf{C P E}$ and $\mathbf{N D I}^{2+}$. We have also shown that the ET dynamics in CPE/acceptor mixtures could be modulated using the supramolecule host cucurbit[7]uril (CB7, Chart 1).
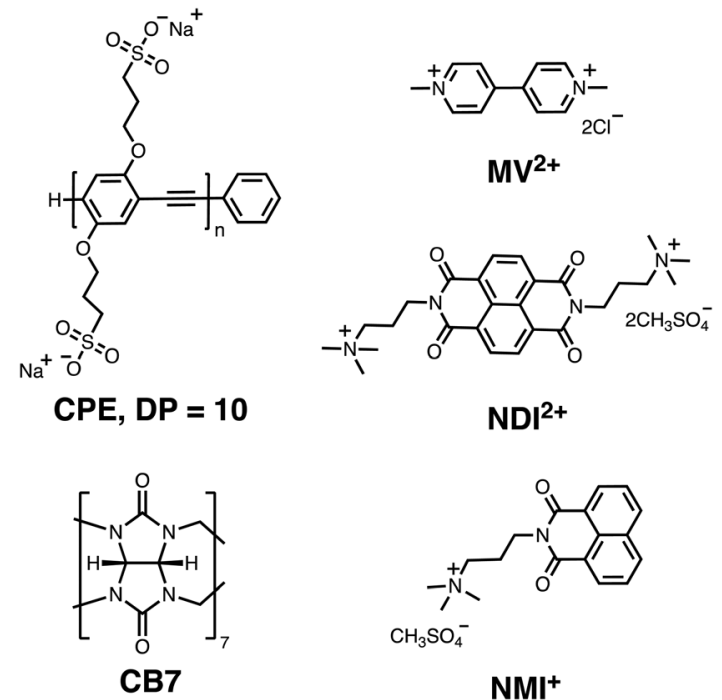

\section{Results}

Structures and thermodynamics of electron transfer

Our primary goal in this work is to elucidate the photoinduced ET mechanism between a water-soluble poly(p-phenylene ethynylene) conjugated polyelectrolyte (CPE) and cationic quenchers. Conjugated polyelectrolyte CPE featuring alkyl sulfonate $\left(\mathrm{R}-\mathrm{SO}_{3}{ }^{-}\right)$was synthesized via a chain-growth polymerization method following an earlier report, and its degree of polymerization $(n)$ was determined to be $\sim 10$ with a polydispersity index (PDI) $\sim 1.2 .{ }^{38}$ Methyl viologen $\left(\mathbf{M V}^{2+}\right)$ and cationic derivatives naphthalene diimide $\left(\mathbf{N D I}^{2+}\right)$ and naphthalene monoimide $\left(\mathbf{N M I}^{+}\right)$were chosen as acceptors because of their capability to associate with the anionic CPE and their strong electron acceptor character. All of the quenchers are mono- or di-cations and therefore are expected to form ion-pair complexes with the anionic polyelectrolyte. Previous work has also shown that polyvalent cations associate more strongly than mono-cations, and in some cases polyvalent ions can induce the formation of aggregates. ${ }^{35,39,40}$

In order to facilitate the discussion below, Fig. 1 gives a simplified excited state scheme for the ion pair complex between $\mathbf{C P E}$ and an acceptor, [CPE, A]. Initial excitation produces the singlet excited state, $\left[{ }^{*} \mathbf{C P E}, \mathbf{A}\right]$, and this can be quenched by forward ET to produce a CT state, represented as $\left[\mathbf{C P E}^{+}, \mathbf{A}^{-}\right]$. This state then relaxes back to the ground state by charge recombination. There is also the possibility that the separation distance between the polymer and reduced acceptor could increase after forward ET occurs, giving rise to a chargeseparated state, $\left[\mathbf{C P E}^{+} / / \mathbf{A}^{-}\right]$. The thermodynamic driving force for forward ET and charge recombination $\left(\Delta G_{\mathrm{f}}\right.$ and $\Delta G_{\mathrm{b}}$, respectively) can be determined from the reduction potentials of the acceptors, and the oxidation potential and the excited state energy of CPE. The relevant potentials are listed in Table 1, along with the excited state oxidation potential of CPE, which is computed from the polymer's ground state oxidation potential, and the singlet excited state 


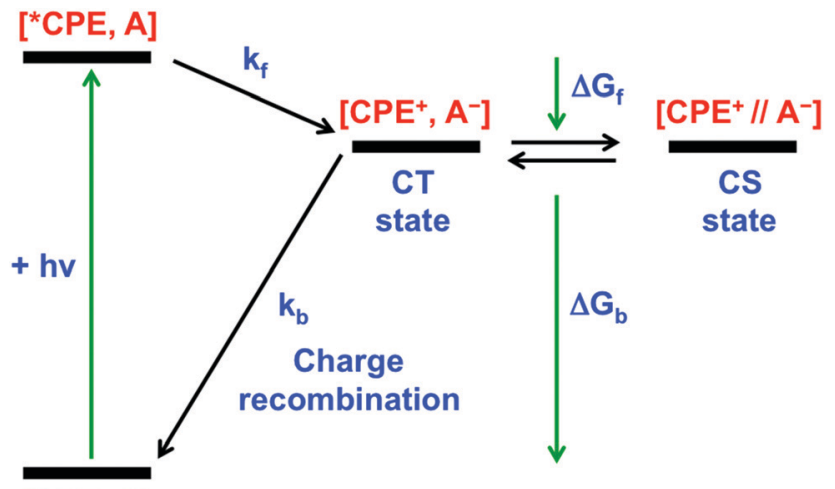

[CPE, A]

Fig. 1 Energy diagram for photoinduced ET and charge recombination in CPE-acceptor ion-pair complexes.

Table 1 Redox potentials for CPE and the acceptors

\begin{tabular}{llll}
\hline Compound & $E\left(\mathbf{C P E} / \mathbf{C P E}^{\bullet+}\right) / \mathrm{V}$ & $E\left({ }^{*} \mathbf{C P E} / \mathbf{C P E}^{\bullet+}\right) / \mathrm{V}^{a}$ & $E\left(\mathbf{A} / \mathbf{A}^{-}\right) / \mathrm{V}$ \\
\hline $\mathbf{C P E}$ & $0.9^{43}$ & -1.8 & - \\
$\mathbf{M V}^{2+}$ & - & - & $-0.46^{44}$ \\
$\mathbf{N D I}^{2+}$ & - & - & $-0.48^{45}$ \\
$\mathbf{N M I}^{+}$ & - & - & $-1.3^{46}$
\end{tabular}

${ }^{a}$ Computed from the following equation, $E\left({ }^{*} \mathbf{C P E} / \mathbf{C P E}^{+}\right)=E\left(\mathbf{C P E} / \mathbf{C P E}^{+}\right)$ - $E\left({ }^{*} \mathbf{C P E}\right)$, where the latter is $2.7 \mathrm{eV}$ and is obtained from the fluorescence maximum of CPE.

energy, $E\left({ }^{*} \mathbf{C P E} / \mathbf{C P E}{ }^{+}\right)=E\left(\mathbf{C P E} / \mathbf{C P E}{ }^{+}\right)-E\left({ }^{*} \mathbf{C P E}\right)$. From the data in Table 1, it is clear that forward ET is very exothermic for all of the acceptors, ranging from $-0.5 \mathrm{eV}$ for $\mathrm{NMI}^{+}$to $-1.34 \mathrm{eV}$ for $\mathbf{M V}^{2+}$. Charge recombination is even more exothermic, ranging from $-1.36 \mathrm{eV}$ for $\mathbf{M V}^{2+}$ to $-2.2 \mathrm{eV}$ for $\mathbf{N M I}^{+}{ }^{41}$ Given the large driving force for all of the ET processes in Fig. 1, it is predicted, assuming that the separation distance in the ion pair complexes is small $(<5 \AA)$, that both forward and return ET will occur rapidly $\left(>10^{9} \mathrm{~s}^{-1}\right)$. This prediction is based on the assumption that the ET reactions will follow a Marcus dependence on the driving force and that the reorganization energy is in the range $0.5-1.0 \mathrm{eV} .^{42}$

\section{Steady state absorption and fluorescence spectroscopy}

The steady-state absorption and fluorescence spectra of CPE and the corresponding complexes with the acceptors were studied in water as a solvent. The fluorescence spectra of the complexes were recorded by exciting at the absorption maximum $(\sim 420 \mathrm{~nm})$ of CPE, where the acceptors do not absorb (Fig. S1, ESI $\dagger$ ). ${ }^{47}$ Fig. 2 illustrates the changes in the absorption and fluorescence spectra of $\mathbf{C P E}$ in the presence of $\mathbf{M V}^{\mathbf{2 +}}$ in water. Addition of $\mathbf{M V}^{2+}(0-7.5 \mu \mathrm{M})$ to $5 \mu \mathrm{M}$ (calculated based on the polymer repeat unit, PRU) CPE resulted in the significant red-shift of the absorption band, which is accompanied by a shoulder peak around $480 \mathrm{~nm}$. The changes are consistent with the spectral changes observed for a CPE and 1,3-propane diammonium salt mixture. ${ }^{48}$ This indicates that the association of $\mathbf{M V}^{2+}$ with $\mathbf{C P E}$ induces a degree of rigidity to the polymer,
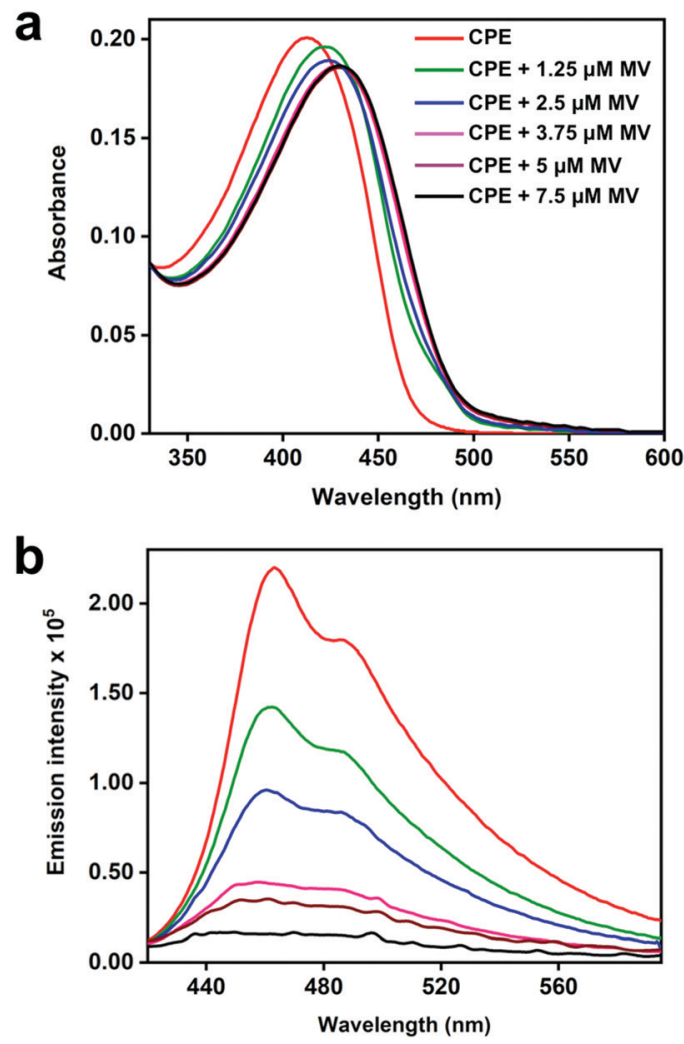

Fig. 2 (a) Absorption and (b) fluorescence spectra $\left(\lambda_{\text {ex }}=410 \mathrm{~nm}\right.$ ) of CPE (5 $\mu \mathrm{M}, \mathrm{PRU})$ in water with varying concentrations of $\mathbf{M V}^{\mathbf{2 +}}$ as indicated in the figure.

restricting its ability to undergo conformational changes, which results in the extension of the conjugation length, which causes the bathochromic shift. ${ }^{35}$ Moreover, the apparent color change (yellow to brown) observed for the $\mathbf{C P E}$ solution upon $\mathbf{M V}^{\mathbf{2 +}}$ addition (Fig. S2, ESI $\dagger$ ) suggests that the absorption spectrum of the $\mathbf{C P E} / \mathbf{M V}^{2+}$ complex may have some contribution from charge transfer absorption. The weak shoulder peak that emerges around $480 \mathrm{~nm}$ is attributed to the absorption of CPE aggregates induced by $\mathbf{M V}^{\mathbf{2 +}} \cdot{ }^{30,31,48}$ The change in $\mathbf{C P E}$ absorption upon $\mathbf{M V}^{\mathbf{2 +}}$ addition is accompanied by a substantial decrease in the fluorescence intensity with $K_{\mathrm{SV}} \sim 7.1 \times 10^{6} \mathrm{M}^{-1} \cdot{ }^{38}$

The absorption and fluorescence spectra of $\mathbf{C P E}$ with the addition of $\mathbf{~ N D I}^{2+}$ and $\mathbf{N M I}^{+}$are shown in Fig. 3. As seen in Fig. 3a and c, the absorbance bands red-shift considerably as a function of the acceptor concentration $(0-10 \mu \mathrm{M})$. For both imide acceptors, the bathochromic shifts of the absorption peaks in the mixtures are more significant compared to $\mathbf{C P E} / \mathbf{M V}^{2+}$, possibly due to the contribution from CT absorption (Fig. S2, ESI $\dagger$ ). The absorption bands observed in the 330-400 $\mathrm{nm}$ region in Fig. $3 \mathrm{a}$ and c correspond to the absorption features of $\mathbf{N D I}^{2+}$ and $\mathbf{N M I}^{+}$(Fig. S1, ESI $\dagger$ ), respectively. Moreover, addition of $\mathbf{N D I}^{2+}$ and $\mathbf{N M I}^{+}$to $\mathbf{C P E}$ also resulted in significant quenching of the CPE fluorescence (Fig. 3b and d) with $K_{\mathrm{SV}} \sim 7.1 \times 10^{6} \mathrm{M}^{-1}$ and $5.5 \times$ $10^{6} \mathrm{M}^{-1}$, respectively (Fig. S3, ESI $\dagger$ ). For all of the samples, the Stern-Volmer plots are approximately linear at low concentration of the quencher but they curve upward at higher concentrations. The $K_{\mathrm{Sv}}$ values were estimated by extrapolating the linear region at 
a

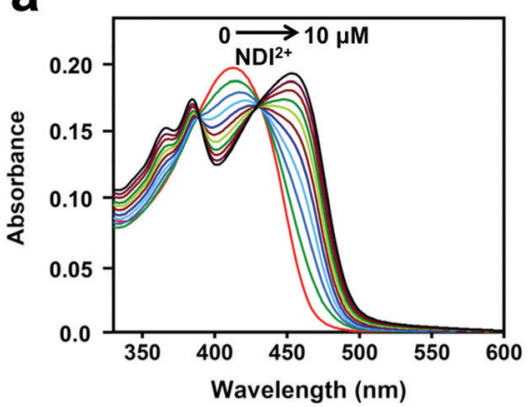

C

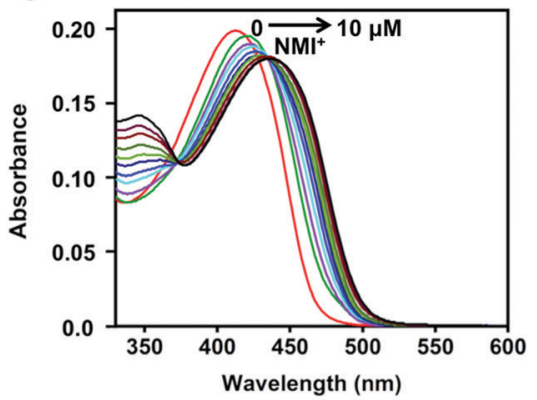

b

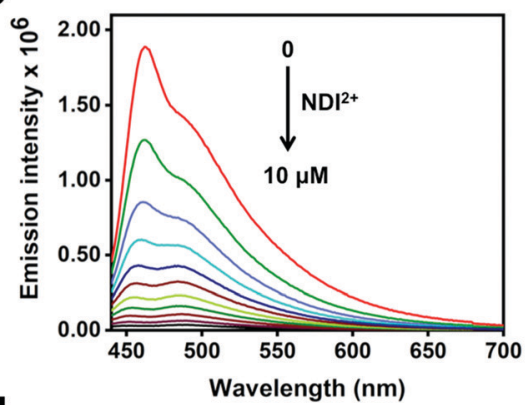

d

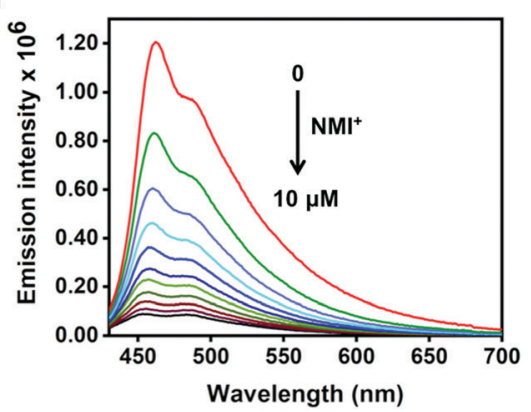

Fig. 3 Absorption spectra of CPE $(5 \mu \mathrm{M}, \mathrm{PRU})$ in water with varying concentrations of (a) $\mathbf{N D I}^{2+}$ and (b) $\mathrm{NMI}^{+}$as indicated in the figures. (b) Fluorescence spectra $\left(\lambda_{\text {ex }}=410 \mathrm{~nm}\right)$ of CPE in water with varying concentrations of (a) $\mathrm{NDI}^{2+}$ and (b) $\mathrm{NMI}^{+}$.

low concentration. Note the subtle effect that the intensity ratio of the $0-0 / 0-1$ vibronic bands changes as a function of quencher concentration, depending on whether the quencher is $\mathbf{N D I}^{2+}$ or $\mathbf{N M I}^{+}$(Fig. 3b and d). This could be caused by the different charges on the quenchers, which leads to different ion-pair/ aggregation interactions in the CPE/quencher complexes.

\section{Picosecond transient absorption spectroscopy}

To obtain more insight into the intermolecular ET between CPE and the cationic electron acceptors, and the absorption features of the polyelectrolyte cation radical $\left(\mathbf{C P E}^{\bullet+}\right)$, picosecond transient absorption (TA) measurements were performed. Fig. 4a displays the TA spectra of CPE in water. The negative signal

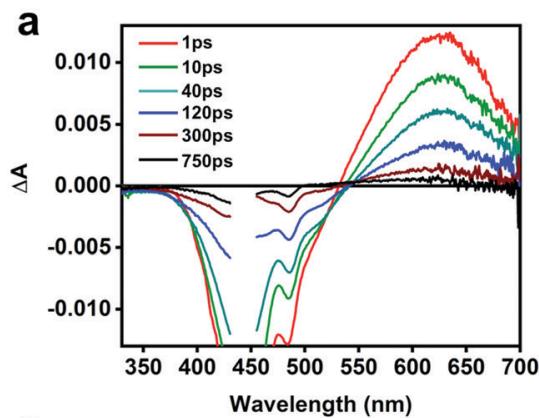

b
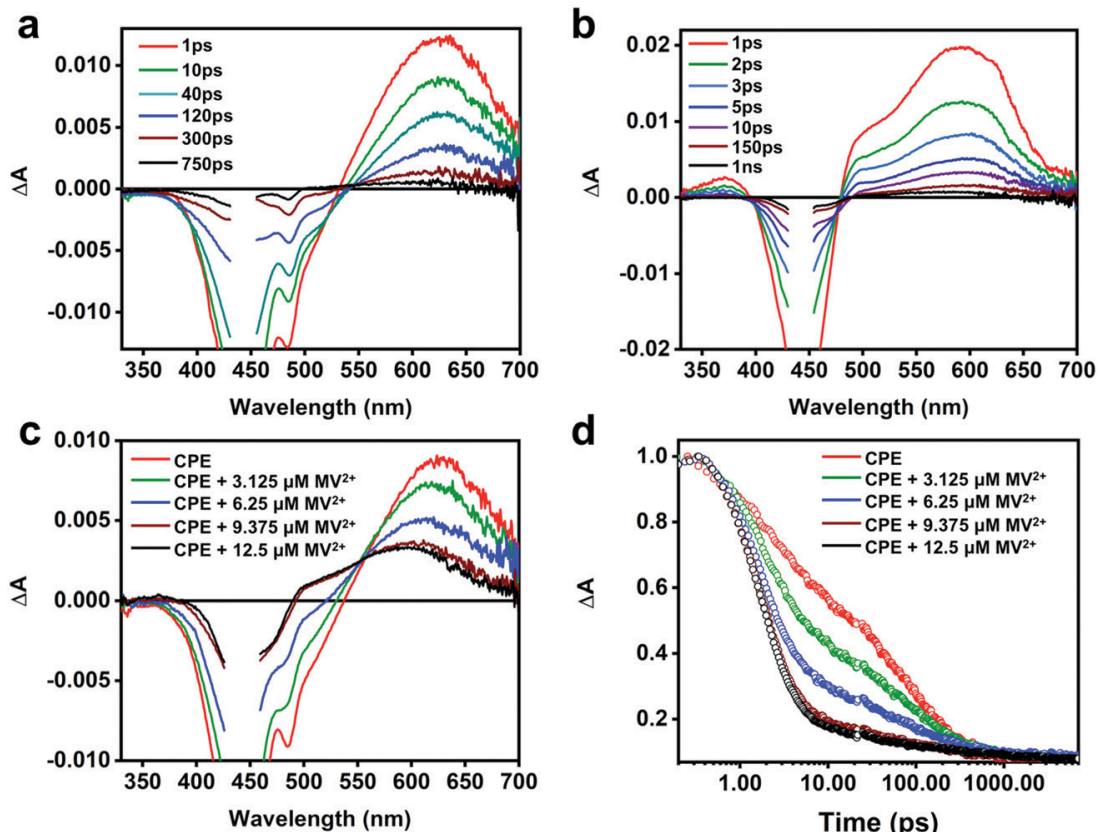

d

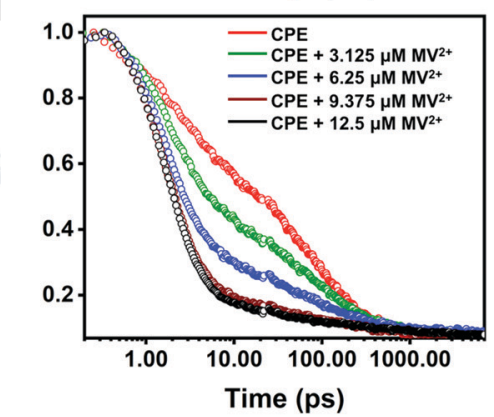

Fig. 4 Picosecond transient absorption (psTA) spectra of (a) CPE (12.5 $\mu \mathrm{M}$, PRU), (b) $\mathrm{CPE}+12.5 \mu \mathrm{M} \mathrm{MV}^{2+}$ at the indicated delay times and (c) $\mathrm{CPE}$ in the presence of $0 \mu \mathrm{M}$ to $12.5 \mu \mathrm{M} \mathrm{MV}^{2+}$ at 10 ps delay time in air-saturated $\mathrm{H}_{2} \mathrm{O}$ following a $440 \mathrm{~nm}$ laser excitation pulse (100 fs pulse width, $100 \mathrm{~nJ}$ per pulse). (d) Kinetic decay traces of $\mathrm{CPE}$ in the presence of $0 \mu \mathrm{M}$ to $12.5 \mu \mathrm{M}$ of $\mathbf{M V}^{2+}$ detected at $603-615 \mathrm{~nm}$. 
observed between 400 and $530 \mathrm{~nm}$ is attributed to stimulated emission (SE) from CPE, which is coupled with broad, featureless absorption in the visible region due to excited state absorption (ESA) of the CPE singlet excited-state. The TA spectrum of CPE is similar to that reported for other PPE-type conjugated polymers. ${ }^{49}$ The ESA kinetics of CPE exhibits three decay components with time constants 3, 49 and 264 ps with relative amplitudes of about $0.41,0.30$ and 0.29 , respectively (Table 1). The fast decay processes $(<50 \mathrm{ps})$ are likely due to initial structural relaxations followed by singlet decay via radiative and non-radiative pathways. The TA decay dynamics for CPE are in good agreement with its fluorescence decay kinetics (Fig. S4, ESI $\dagger$ ).

The TA spectra of $\mathbf{C P E}$ with $\mathbf{M V}^{2+}$ (1:1 concentration ratio) recorded at different delay times are shown in Fig. $4 \mathrm{~b}$ and a comparison of the spectra at 10 ps delay time for CPE with various $\mathbf{M V}^{2+}$ concentrations is shown in Fig. 4c (see Fig. S5 in the ESI $\dagger$ for full spectra). From these data it is clear that the TA spectra for the $\mathbf{C P E} / \mathbf{M V}^{2+}$ complex are noticeably different from those of CPE alone. In particular, the main absorption band in the spectrum in the presence of $\mathbf{M V}^{2+}$ is blue shifted from that of CPE alone, and in addition there is substantially more absorption in the region between 330 and $500 \mathrm{~nm}$ (the latter is partially due to the decrease in $\mathrm{SE}$ due to fluorescence quenching in the $\mathbf{C P E} / \mathbf{M V}^{2+}$ complex). The TA spectrum of the $\mathbf{C P E} / \mathbf{M V}^{2+}$ complex is dominated by the absorption of the oxidized polymer $\left(\mathbf{C P E}^{\bullet+}\right.$, polaron state). This assignment is supported by a previous study of a structurally-similar PPE-based polymer cation radical generated by pulse radiolysis which displayed a similar absorption-difference spectrum. ${ }^{50}$ Note that the spectrum of the oxidized polymer $\left(\mathbf{C P E}^{\bullet+}\right.$, polaron state) is similar to that of the singlet exciton state; however, it is not unusual for exciton and polaron states of conjugated polymers to have similar spectra. ${ }^{51}$ Notable is the fact that the spectral signature of the reduced acceptor $\left(\mathbf{M V}^{\mathbf{}}\right)$, which displays bands at 395 and $600 \mathrm{~nm},{ }^{47,52}$ is not seen in the transient absorption spectrum of the $\mathbf{C P E} / \mathbf{M V}^{2+}$ complex. It is not clear why this is the case, but it may be due to the fact that the $395 \mathrm{~nm}$ band is obscured by the excitation scattering and $\mathrm{SE}$, and the $600 \mathrm{~nm}$ band is overlapped by the significantly stronger absorption of $\mathbf{C P E}^{\bullet+}$.

As shown in Fig. 4d, addition of $\mathbf{M V}^{2+}$ to $\mathbf{C P E}$ leads to two notable changes in the TA decay dynamics. First, the predominant decay component is considerably more rapid in $\mathbf{C P E} / \mathbf{M V}^{2+}$ compared to CPE. Second, less obvious is the low amplitude, long lifetime component $(\tau>1000 \mathrm{ps})$ that emerges at higher $\mathbf{M V}^{2+}$ concentration (see Table 2). As discussed in more detail below, analysis of the kinetics suggests that the photoinduced ET occurs on an ultrafast timescale $\left(k_{\mathrm{f}}>10^{12} \mathrm{~s}^{-1}\right)$ and the dominant decay component in the TA is due to return ET ( $2 \mathrm{ps}, k_{\mathrm{b}} \sim 5 \times 10^{11} \mathrm{~s}^{-1}$ ), which gives rise to decay of the absorption. The long lifetime component apparent in samples with higher $\mathbf{M V}^{\mathbf{2}}$ concentration is due to a small component of $\mathbf{C P E}^{\bullet^{+}}$(polaron) $/ / \mathbf{M V}^{\bullet+}$ pairs that are able to undergo cage escape from the original complex geometry where CT occurs. This gives rise to a decreased rate of charge recombination
Table 2 Picosecond transient absorption kinetics

\begin{tabular}{llcl}
\hline & $\tau_{1} / \mathrm{ps}$ & $\tau_{2} / \mathrm{ps}$ & $\tau_{3} / \mathrm{ps}$ \\
\hline $\mathbf{C P E}$ & $3.0 \pm 0.2(0.41)$ & $49 \pm 6(0.30)$ & $264 \pm 24(0.29)$ \\
$\mathbf{C P E} / \mathbf{M V}^{2+}$ & $2.0 \pm 0.1(0.89)$ & $115 \pm 10(0.08)$ & $>1000(0.03)$ \\
$\mathbf{C P E} / \mathbf{M V}^{2+} / \mathbf{C B} 7$ & $4.0 \pm 0.2(0.41)$ & $60 \pm 6 \mathrm{ps}(0.30)$ & $610 \pm 60(0.29)$
\end{tabular}

The relative amplitudes are in parentheses. $\mathbf{C P E}=12.5 \mu \mathrm{M}, \mathbf{M V}^{2+}=$ $12.5 \mu \mathrm{M}$ and $\mathbf{C B 7}=125 \mu \mathrm{M}$.

(Fig. 1), which manifests as a much slower decay rate for the $\mathbf{C P E}^{\bullet+}$ (polaron) absorption.

In order to better under the ET process and to identify the acceptor anion radical, we utilized a naphthalene dimiide $\left(\right.$ NDI $\left.^{2+}\right)$ electron acceptor. The spectrum of the reduced diimide $\left(\mathrm{NDI}^{+}\right)$has been well documented in previous spectroelectrochemical and transient absorption studies. ${ }^{53-55}$ Fig. 5a illustrates the TA difference spectra of the $\left[\mathbf{C P E}, \mathbf{N D I}^{2+}\right]$ ion-pair complex recorded at different delay times. The spectra feature strong negative absorption features located from 330 to $470 \mathrm{~nm}$ that are consistent with the depopulation of the electronic ground states of $\mathbf{C P E}$ and $\mathbf{N D I}^{2+}$ (i.e., ground state bleaching). The positive transient absorption consists of two prominent bands. The most significant signal to emerge is the narrow absorption band at $\sim 490 \mathrm{~nm}$, which is partially cut-off by the

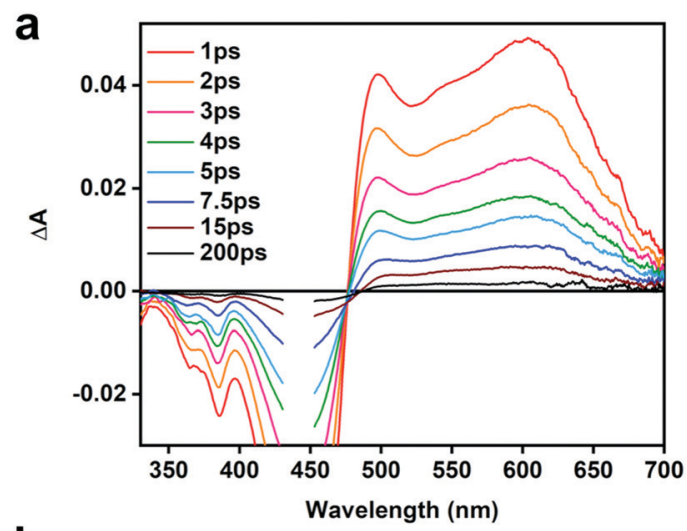

b

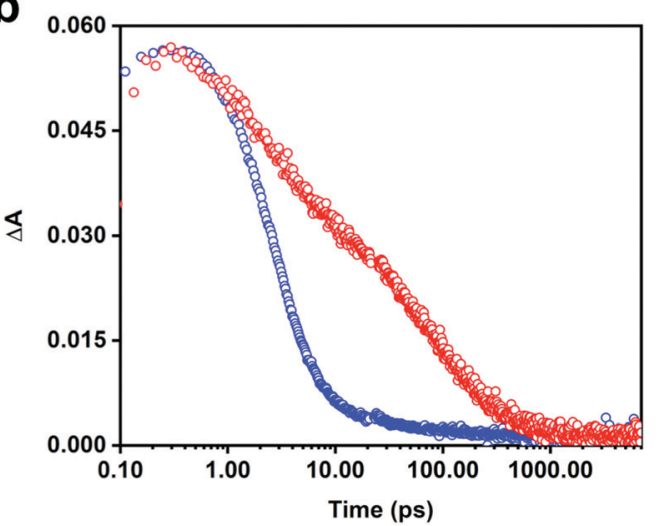

Fig. 5 (a) Picosecond TA spectra of CPE (12.5 $\mu \mathrm{M}, \mathrm{PRU})+12.5 \mu \mathrm{M} \mathrm{NDI}^{2+}$ in air-saturated $\mathrm{H}_{2} \mathrm{O}$ at the indicated delay times following a $440 \mathrm{~nm}$ laser excitation pulse (100 fs pulse width, $100 \mathrm{~nJ}$ per pulse). (b) Kinetic decay traces of CPE (red) and CPE $+\mathbf{N D I}^{2+}$ (blue) detected at $603 \mathrm{~nm}$ and $622 \mathrm{~nm}$, respectively. 
ground state bleach of CPE. This absorption is clearly due to the reduced diimide acceptor (e.g., $\mathbf{N D I}^{\mathbf{}^{+}}$) resulting from the photoinduced ET from $\mathbf{C P E}$ to $\mathbf{N D I}^{2+}$. The broad transient absorption that extends from $500-650 \mathrm{~nm}$ is mainly due to the $\mathbf{C P E}^{\bullet+}$ (polaron) state as it is similar in shape and peak wavelength compared to that observed for the polaron absorption in the CPE/MV ${ }^{2+}$ system (Fig. 4b). The dynamics for the $\mathbf{C P E} / \mathbf{N D I}^{2+}$ system are shown in Fig. $5 \mathrm{~b}$; it can be seen that the charge transfer state decays very rapidly, with a dominant decay component of 3 ps (Table S2, ESI $\dagger$ ).

The intermolecular ET between CPE and dicationic electron acceptors occurs very rapidly because of the strong ion-pair complex formation. To test the efficiency of the electron transfer process between CPE and a monocationic acceptor, identical experiments were carried out with a naphthalene monomiide $\left(\mathbf{N M I}^{+}\right)$derivative. The TA spectrum of $\mathbf{C P E} / \mathbf{N M I}^{+}$ at 13 ps delay (Fig. S6a, ESI $\dagger$ ) is qualitatively similar to the spectrum with the $\mathbf{N D I}^{2+}$ acceptor, supporting its assignment to the charge-transfer state $\left[\mathbf{C P E}^{\bullet+}, \mathbf{N M I}^{\bullet}\right]$ produced by ultrafast photoinduced ET from $\mathbf{C P E}$ to the $\mathbf{N M I}^{+}$acceptor. This species decays with single exponential kinetics with a lifetime of 35 ps (Table S3, ESI $\dagger$ ).

\section{Modulation of the electron transfer dynamics using cucurbit[7]uril}

It is well known from previous studies that the energy and ET dynamics between donor and acceptor molecules could be modulated using supramolecules, in which one of the donor or acceptor is trapped within the cavity of a supramolecule and the other remains free in solution or electrostatically bound to the outside of its wall. ${ }^{56-60}$ Cucurbit[7]uril (CB7, Chart 1) is a water-soluble barrel-shaped organic macrocyclic host molecule composed of seven glycoluril units interlinked to each other by pairs of methylene groups. ${ }^{61,62}$ Host-guest complexation in CB7 is driven by the hydrophobic interactions of a guest molecule with its inner cavity, and electrostatic attraction of cationic groups on the guest towards $\mathrm{C}=\mathrm{O}$ dipoles on $\mathbf{C B} 7 .{ }^{63}$

To probe the feasibility of modulating the ET dynamics of the $\left[\mathbf{C P E}, \mathbf{M V}^{2+}\right]$ ion pair complex, $\mathbf{C B 7}$, which is known to strongly bind $\mathbf{M V}^{2+}$ (association constant, $K_{\mathrm{a}} \sim 2 \times 10^{5} \mathbf{M}^{-1}$ ) 64 in aqueous medium, was used as a host. Fig. $6 \mathrm{a}$ and b display the changes in the absorption and fluorescence spectra of the $\mathbf{C P E} / \mathbf{M V}^{2+}$ mixture in the presence of $\mathbf{C B} 7$. Upon incremental addition of $\mathbf{C B} 7(0-100 \mu \mathrm{M})$, the intensity of the absorption peak increased monotonically with a concomitant blue shift, which is accompanied by an increase in the fluorescence intensity. The fluorescence recovery confirms the interference of $\mathbf{C B} 7$ in the ET quenching process. Nevertheless, the fluorescence was not fully recovered even in the presence of $100 \mu \mathrm{M}$ CB7 and it also resulted in a featureless fluorescence band. This suggests that CB7 may slow the rate of ET quenching $\left(e . g ., k_{\mathrm{f}}\right.$ in Fig. 1), but not shut off ET entirely.

Although the TA spectra (Fig. 6c) of the $\mathbf{C P E} / \mathbf{M V}^{2+} / \mathbf{C B 7}$ mixture are complex, several important conclusions can be derived based on the spectral features and kinetics. First, the TA spectral features in the shorter time range (1 ps-60 ps) and the lifetimes ( 4 and $60 \mathrm{ps}$ ) are consistent with the spectral and decay kinetics of CPE alone (Fig. 4 and 6d, and Table 2). Secondly, the TA spectra at longer delay times blue-shift by $\sim 20 \mathrm{~nm}$ and the long lifetime component of the $\mathbf{C P E} / \mathbf{M V}^{2+} / \mathbf{C B} 7$
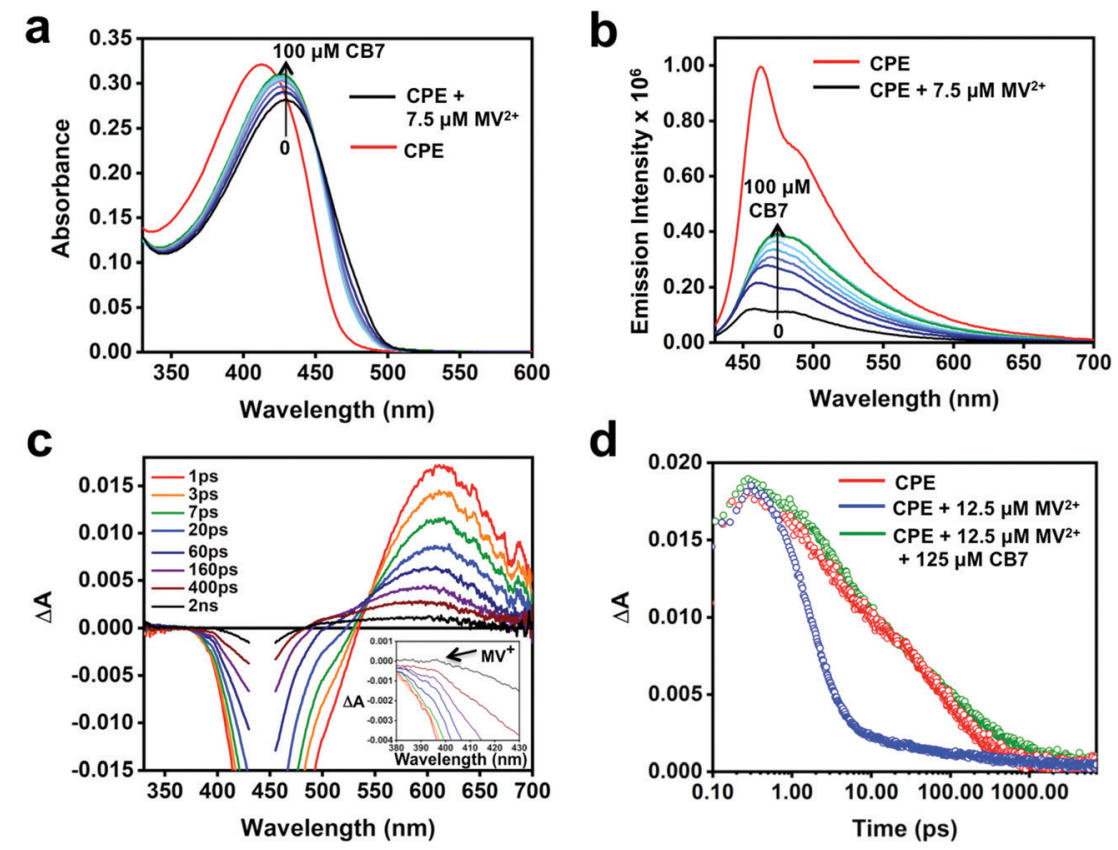

Fig. 6 (a) Absorption and (b) fluorescence $\left(\lambda_{\mathrm{ex}}=410 \mathrm{~nm}\right)$ spectra of CPE $(5 \mu \mathrm{M}, \mathrm{PRU})+\mathrm{MV}^{2+}$ in water with varying concentrations of CB7 as indicated in the figure. (c) Picosecond TA spectra of the $\mathbf{C P E} / \mathbf{M V}^{2+} / \mathbf{C B 7}$ mixture $\left(\mathrm{CPE}=12.5 \mu \mathrm{M}, \mathbf{M V}^{2+}=12.5 \mu \mathrm{M}, \mathbf{C B 7}=125 \mu \mathrm{M}\right)$ in $\mathrm{H}_{2} \mathrm{O}$ at the indicated delay times following a $440 \mathrm{~nm}$ laser excitation pulse (100 fs pulse width, $100 \mathrm{~nJ}$ per pulse). (d) Kinetic decay traces of CPE (red), CPE/MV ${ }^{2+}(\mathrm{blue})$ and $\mathrm{CPE} / \mathrm{MV}^{2+} / \mathrm{CB} 7$ (green) detected at $603 \mathrm{~nm}, 615 \mathrm{~nm}$ and $606 \mathrm{~nm}$, respectively. 
decay is slower $(\sim 610 \mathrm{ps})$ than that of CPE $(\sim 264 \mathrm{ps}$, Table 2$)$. Global analysis of the time-resolved spectral dynamics (Fig. S7, ESI $\dagger$ ) clearly shows that the slowly decaying component has blue-shifted absorption that is similar to that observed for the [CPE, $\left.\mathbf{M V}^{2+}\right]$ complex (Fig. 4b).

Although the TA feature of $\mathbf{C P E}^{\mathbf{}^{+}}$is not clearly visible for $\mathbf{C P E} / \mathbf{M V}^{2+} / \mathbf{C B} 7$, careful inspection of the signals at $0.4-2 \mathrm{~ns}$ delay times in Fig. $6 \mathrm{c}$ reveals the presence of weak absorption of $\mathbf{C P E}^{\bullet+}$ along with very weak absorption at $\sim 395 \mathrm{~nm}$ that may be due to the reduced viologen acceptor, $\mathbf{M V}^{\bullet+}$ (Fig. 6c inset). Taken together, the data for the $\mathbf{C P E} / \mathbf{M V}^{2+} / \mathbf{C B} 7$ system suggest that $\mathbf{C B} 7$ sequesters $\mathbf{M V}^{2+}$ from $\mathbf{C P E}$, slowing the rate of forward ET due to separation of $\mathbf{C P E}$ from $\mathbf{M V}^{2+}$ by the $\mathbf{C B} 7$ wall. This gives rise to a longer lifetime for ${ }^{*} \mathbf{C P E}$ and suppressed fluorescence quenching. The rate of return ET $\left(k_{\mathrm{b}}\right)$ may also be suppressed by CB7, also due to the separation imparted by the host.

The absorption and fluorescence spectra of $\mathbf{C P E} / \mathbf{N D I}^{2+}$ in the presence of $\mathbf{C B 7}$ are shown in Fig. S7a and b (ESI $\dagger$ ), respectively. Given the smaller size of the inner cavity of $\mathbf{C B 7}$, it is expected that $\mathbf{N D I}^{2+}$ will not form a host-guest complex with CB7. The absence of any considerable change in the absorption and fluorescence spectra of the $\mathbf{C P E} / \mathbf{N D I}^{2+}$ mixture confirmed the inability of $\mathbf{C B 7}$ to alter the interaction of CPE and $\mathbf{N D I}^{2+}$.

\section{Discussion}

Following the pioneering work of Wudl and Heeger on ultrafast ET in PPV-based conjugated polymer/C60 systems and on bulk heterojunction solar cells, ${ }^{65,66}$ the rich photophysical properties of conjugated polymers/CPEs and their ability to participate in photoinduced ET processes have been exploited for their application as organic photovoltaics and sensors. Although the electron-donating feature of conjugated polyelectrolytes has been successfully utilized for a range of applications, systematic investigation of the polaron state of the polyelectrolytes resulting from photoinduced ET has not been reported previously. In this context, understanding the ET mechanism and dynamics as well as the photophysics of polaron states of conjugated systems is essential for the advancement of the field. Earlier work reported by Friend and coworkers on TA spectroscopy studies of a poly $\left(9,9^{\prime}\right.$-dioctylfluorenealt-benzothiadiazole) based CPE revealed the generation of polaron states in the absence of electron acceptors as a result of inter-chain exciton annihilation. ${ }^{67}$ They also observed that the polarons are stabilized in the solid state by counter anions via Coulombic interaction. Clark et al. performed TA studies for a PPE-based polyelectrolyte in its aggregated state in ethanol. Their attempts to detect the polaron signals of the polyelectrolyte were unsuccessful due to the lack of effective interchain interactions. ${ }^{68}$

The primary objective of this work was to study the mechanism of quenching of a water-soluble PPE-based conjugated polyelectrolyte by electron acceptors, with the aim to observe the CT state and its spectral properties and dynamics. For all three CPE/acceptor mixtures, a considerable red-shift in the absorption was readily observed in the steady-state absorption spectra and their intensities are comparable to the main band of CPE. The bathochromic shift is caused as a result of the suppression of polymer conformational changes upon association with the cationic acceptors, and also the possibility of absorption due to optical CT. Moreover, the electron acceptors quenched the fluorescence from CPE very efficiently with Stern-Volmer quenching constants $\left(K_{\mathrm{SV}}\right)$ in excess of $10^{6} \mathrm{M}^{-1}$, consistent with the amplified quenching effect. Addition of a supporting electrolyte such as $\mathrm{NaCl}$ (Fig. S9, ESI $\dagger$ ) to $\mathbf{C P E} / \mathbf{M V}^{\mathbf{2 +}}$ resulted in the dissociation of $\mathbf{C P E}$ and $\mathbf{M V}^{\mathbf{2}}$, which is evident from the recovery of the CPE fluorescence in Fig. S9b (ESI $\dagger$ ). Moreover, the bathochromic shift in the absorption spectra of $\mathbf{C P E} / \mathbf{M V}^{2+} / \mathbf{N a C l}$ (Fig. S9a) (ESI $\dagger$ ) suggests that the polymer aggregates at high ionic strength due to polyelectrolyte charge screening by $\mathrm{NaCl}^{30}{ }^{30}$ The distinct absorption features of the polymer aggregates and $\mathbf{C P E} / \mathbf{M V}^{2+}$ further confirm that the $\mathbf{C P E} / \mathbf{M V}^{2+}$ ion-pair complex mostly remains as individual chains and the binding of $\mathbf{M V}^{\mathbf{2}}$ to $\mathbf{C P E}$ suppresses the polymer conformational changes. Taken together, the pronounced changes in the absorption and fluorescence spectra of the mixtures suggest: (1) that there is tight (ion-pair) association between anionic CPE and the cationic acceptors; and (2) that photoinduced ET between the polyelectrolyte and quenchers occurs rapidly and efficiently.

The ultrafast TA studies provided some interesting details about the ET properties and the CT states of CPE and the acceptors. The TA spectra of $\left[\mathbf{C P E}, \mathbf{M V}^{2+}\right]$ (Fig. 3b) revealed the absorption feature of $\mathbf{C P E}^{\bullet+}$ generated as a result of the photoinduced ET to $\mathbf{M V}^{2+}$, which is unprecedented for any PPE-type polyelectrolytes. The spectrum of the polaron state of the PPE-based polymer exhibits a primary band maximum at $\sim 595 \mathrm{~nm}$, and it is in agreement with previous studies on PPE-type oligomers and polymers. ${ }^{69}$ Moreover, the absorption feature due to the reduced acceptor, $\mathbf{M V}^{\bullet+}$, which is expected at $\sim 395 \mathrm{~nm}$, was not observed for $\mathbf{C P E} / \mathbf{M V}^{2+}$. It is unclear why, but it is possible that it is obscured by the considerably more intense bleach and absorption features due to $\mathbf{C P E}^{\mathbf{}}{ }^{+}$. However, direct evidence for the existence of the CT state is obtained from the TA spectra of the $\left[\mathbf{C P E}, \mathbf{N D I}^{2+}\right]$ ion-pair complex (Fig. 5a). In this case, clear absorption bands due to the oxidized CPE and the reduced diimide acceptor can be seen, and these are formed essentially instantaneously following photoexcitation of $\mathbf{C P E}(<1 \mathrm{ps})$, indicating that the forward ET is ultrafast $\left(k_{\mathrm{f}}>10^{12} \mathrm{~s}^{-1}\right)$.

As noted above, the forward ET in both the $\left[\mathbf{C P E}, \mathbf{M V}^{2+}\right]$ and $\left[\mathbf{C P E}, \mathbf{N D I}^{2+}\right]$ complexes is ultrafast. This is evident from the fact that the spectra of the CT states are observed at even the earliest delay times probed $\left(1 \mathrm{ps}, k_{\mathrm{f}}>10^{12} \mathrm{~s}^{-1}\right)$. In both systems, the predominant kinetic decay component for the CT state has $\tau \sim 3 \mathrm{ps}$, and we attribute this process to return ET from the CT state $\left(k_{\mathrm{b}} \sim 3 \times 10^{11} \mathrm{~s}^{-1}\right)$. The very fast ET dynamics in these systems are readily explained by the following features. First, the distance between the polymer backbone and the acceptor is likely very short (Fig. 7a), giving rise to relatively strong electronic coupling $\left(V_{\mathrm{el}}>50 \mathrm{meV}\right) .{ }^{42}$ Second, for both the $\mathbf{M V}^{2+}$ and $\mathbf{N D I}^{2+}$ acceptors, the driving force for the forward and 
a

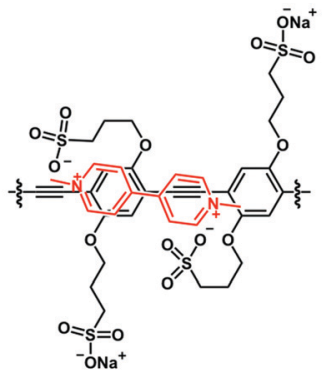

b

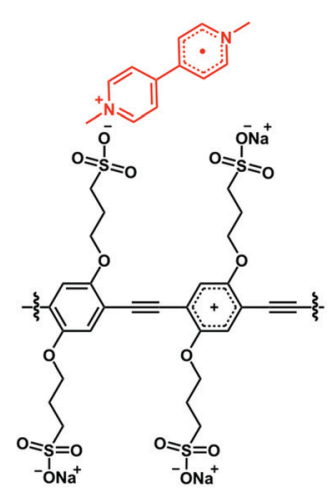

Fig. 7 Possible structure of ion-pair complexes. (a) $\left[\mathrm{CPE}, \mathrm{MV}^{2+}\right]$ and (b) $\left[\mathrm{CPE}^{\bullet+}, \mathrm{MV}^{\bullet+}\right]$.

return ET processes is in the range of $-1.3 \mathrm{eV}$, making them highly exothermic (near the activationless region of the Marcus curve). One subtle yet interesting feature is the existence of a low-amplitude, slow decay component for the CT state for the $\left[\mathbf{C P E}, \mathbf{M V}^{2+}\right]$ complex, suggesting a mechanism that gives rise to slower return ET. It is possible that the slower process is due to the formation of a "separated" CT state, where the reduced acceptor $\mathbf{M V}^{\bullet+}$ has diffused away from the backbone, perhaps by becoming bound to only one of the polyelectrolyte pendant anion groups $\left(-\mathrm{R}^{-} \mathrm{SO}_{3}{ }^{-}\right)$, e.g., Fig. $7 \mathrm{~b}$.

Photoinduced ET between a donor and acceptor pair, especially ones that form ground-state CT complexes, is a very rapid process that occurs usually on a sub-picosecond time scale. ${ }^{70-72}$ Designing donor-acceptor systems in which the deacceleration of return ET could lead to elongation of the lifetime of the charge-separated state is essential for the efficient conversion of light to chemical energy. One of the interesting and facile approaches adopted to slow down the return ET process is through screening the donor from the acceptor or vice versa using an insulating supramolecular host. ${ }^{73-75}$ To the best of our knowledge, this strategy has not been employed for the deacceleration of the ET process in conjugated polyelectrolytes. For modulating the electron transfer process in the CPE/acceptor systems, the rigid supramolecule $\mathbf{C B} 7$ was employed. Our results indicate that since $\mathbf{C B} 7$ has the ability to fully encapsulate $\mathbf{M V}^{2+}{ }^{64}$ the host-guest $\left(\mathbf{M V}^{\mathbf{2 +}} / \mathbf{C B} 7\right)$ complex formed upon addition of $\mathbf{C B 7}$ to $\mathbf{C P E} / \mathbf{M V}^{2+}$ remains bound to the polyelectrolyte, allowing the ET to proceed through the walls of the host. As a result, the forward and return ET processes are slowed down in the $\mathbf{C P E} / \mathbf{M V}^{2+} / \mathbf{C B} 7$ system. By contrast, $\mathbf{C B} 7$ did not influence the ET process in $\mathbf{C P E} / \mathbf{N D I}^{2+}$ due to the inability of $\mathbf{C B} 7$ to form a host-guest complex with $\mathbf{N D I}^{2+}$. Thus, the results provided a proof-of-concept for the modulation of the ET process in mixtures involving conjugated polyelectrolytes.

\section{Conclusion}

In this report, we investigated the photoinduced ET properties of a water-soluble $\operatorname{poly}(p$-phenylene ethynylene) conjugated polyelectrolyte appended with alkyl sulfonate $\left(\mathrm{R}_{-} \mathrm{SO}_{3}{ }^{-}\right)$functionality in the presence of three strong electron acceptors. Direct observation of the red-shift in the absorption peaks revealed the ion-pair assembly formation between the polyelectrolyte and quenchers. The fluorescence of the polyelectrolyte is quenched very efficiently with Stern-Volmer constants $\left(K_{\mathrm{SV}}\right)$ on the order of $10^{6} \mathrm{M}^{-1}$. Ultrafast transient absorption studies of the CPE/acceptor complexes revealed the unprecedented absorption feature of the cation radical species of the PPEbased polyelectrolyte. The TA spectra of the $\left[\mathbf{C P E}, \mathbf{N D I}^{2+}\right]$ complex provided further evidence for the production of anion radical species of the acceptor via photoreduction. Kinetics measurements performed on the three polyelectrolyte/acceptor mixtures indicate that the forward ET occurs with rate constant $k_{\mathrm{f}}>1 \times$ $10^{12} \mathrm{~s}^{-1}$ and the return ET is also rapid with $k \sim 3 \times 10^{11} \mathrm{~s}^{-1}$.

\section{Experimental section}

\section{Characterization methods}

UV-visible spectra were recorded using a Shimadzu UV-2600 spectrophotometer. Corrected steady-state fluorescence spectra were obtained using an Edinburgh fluorometer. A $1 \mathrm{~cm}^{2}$ square pyrex cuvette was used for the solution spectra, and the emission was collected at $90^{\circ}$ relative to the excitation beam. Fluorescence lifetimes were measured using a PicoQuant FluoTime 300 fluorescence lifetime spectrophotometer by time-correlated single photon counting (PicoQuant PicoHarp 300 module). A high-performance LDH-D-C-405 PicoQuant diode laser provided the excitation at $405 \mathrm{~nm}$ (repetition rate $40 \mathrm{MHz}$, $P<3 \mathrm{~mW}$ ) for the sample. The instrument response function (ca. 100 ps) was measured using a Ludox scattering solution. Decays were obtained using single/biexponential fitting parameters using FluoroFit software.

Femtosecond-picosecond transient absorption spectroscopy was carried out using a system consisting of a Coherent Astrella Ti:sapphire (100 fs, $1 \mathrm{KHz}$ repetition) source (https://www. coherent.com/lasers/laser/astrella-ultrafast-tisapphire-amplifier) coupled with an Opera Solo OPA (https://www.coherent.com/ lasers/laser/opera-solo-ultrafast-optical-parametric-amplifier) and a Ultrafast Systems Helios transient absorption spectrometer (https:/ultrafastsystems.com/products/helios-fire). The first beam generated from the Coherent Astrella was directed through an optical parametric amplifier in the Opera Solo OPA, where the wavelength was tuned to $440 \mathrm{~nm}$ for pumping. The pump beam was then directed into a Helios fire (Ultrafast) automated femtosecond transient absorption spectrometer where the beam passed through a chopper, depolarizer and neutral density filter to tune the beam to $0.1 \mathrm{~mW}(100 \mathrm{~nJ}$ per pulse) of power before hitting the stirred sample (O.D. $\approx 0.2$ ). The second beam was passed through a digitally controlled delay stage (in the Helios fire) with a maximum range of $8 \mathrm{~ns}$, and afterward the beam was focused into a calcium fluoride crystal to generate a UV-visible probe ranging from 320-700 $\mathrm{nm}$. The two beams overlap at the sample position with their respective electronic polarizations at the magic angle. The output signal with 
and without pumping (at several time delays) was detected using a fiber-coupled alignment-free spectrometer with a 1024-pixel CMOS sensor. Chirp- and time-zero corrected spectra, and multiexponential decay fits were acquired and manipulated using Surface Explorer software provided by Ultrafast Systems. OriginLab Corporation (version 9.55) data analysis software was used to plot the spectra.

\section{Conflicts of interest}

There are no conflicts to declare.

\section{Acknowledgements}

We acknowledge the Welch Foundation for support through the Welch Chair (Grant No. AX-0045-20110629).

\section{References}

1 H. Jiang, P. Taranekar, J. R. Reynolds and K. S. Schanze, Conjugated Polyelectrolytes: Synthesis, Photophysics, and Applications, Angew. Chem., Int. Ed., 2009, 48, 4300-4316.

2 Y. Liu, K. Ogawa and K. S. Schanze, Conjugated Polyelectrolytes as Fluorescent Sensors, J. Photochem. Photobiol., C, 2009, 10, 173-190.

3 B. Liu and G. C. Bazan, Conjugated Polyelectrolytes Fundamentals and Applications, Wiley-VCH, Weinheim, 2013.

4 X. Zhao, M. R. Pinto, L. M. Hardison, J. Mwaura, J. Müller, H. Jiang, D. Witker, V. D. Kleiman, J. R. Reynolds and K. S. Schanze, Variable band gap poly (arylene ethynylene) conjugated polyelectrolytes, Macromolecules, 2006, 39, 6355-6366.

5 A. O. Patil, Y. Ikenoue, F. Wudl and A. J. Heeger, Water soluble conducting polymers, J. Am. Chem. Soc., 1987, 109, 1858-1859.

6 J. H. Seo, E. B. Namdas, A. Gutacker, A. J. Heeger and G. C. Bazan, Conjugated Polyelectrolytes for Organic Light Emitting Transistors, Appl. Phys. Lett., 2010, 97, 043303.

7 C. Duan, L. Wang, K. Zhang, X. Guan and F. Huang, Conjugated Zwitterionic Polyelectrolytes and Their Neutral Precursor as Electron Injection Layer for High-Performance Polymer Light-Emitting Diodes, Adv. Mater., 2011, 23, 1665-1669.

8 W. Lee, J. H. Seo and H. Y. Woo, Conjugated Polyelectrolytes: A New Class of Semiconducting Material for Organic Electronic Devices, Polymer, 2013, 54, 5104-5121.

9 A. Duarte, K.-Y. Pu, B. Liu and G. C. Bazan, Recent Advances in Conjugated Polyelectrolytes for Emerging Optoelectronic Applications, Chem. Mater., 2011, 23, 501-515.

10 J. Kesters, T. Ghoos, H. Penxten, J. Drijkoningen, T. Vangerven, D. M. Lyons, B. Verreet, T. Aernouts, L. Lutsen, D. Vanderzande, J. Manca and W. Maes, Imidazolium-Substituted Polythiophenes as Efficient Electron Transport Materials Improving Photovoltaic Performance, Adv. Energy Mater., 2013, 3, 1180-1185.
11 Y. Yuan, J. Liu and B. Liu, Conjugated-PolyelectrolyteBasedpolyprodrug:Targeted and Image-Guided Photodynamic and Chemotherapy with on-Demand Drug Release Upon Irradiation with a Single Light Source, Angew. Chem., Int. Ed., 2014, 53, 7163-7168.

12 P. Jagadesan, Y. Huang and K. S. Schanze, in Conjugated Polymers: Perspective, Theory, and New Materials, Taylor \& Francis, 2019, pp. 547-587.

13 G. Feng, C.-K. Mai, R. Zhan, G. C. Bazan and B. Liu, Narrow Band Gap Conjugated Polyelectrolytes for Photothermal Killing of Bacteria, J. Mater. Chem. B, 2015, 3, 7340-7346.

14 Y. Huang, H. C. Pappas, L. Zhang, S. Wang, R. Cai, W. Tan, S. Wang, D. G. Whitten and K. S. Schanze, Selective Imaging and Inactivation of Bacteria over Mammalian Cells by Imidazolium-Substituted Polythiophene, Chem. Mater., 2017, 29, 6389-6395.

15 C. Zhu, Q. Yang, L. Liu, F. Lv, S. Li, G. Yang and S. Wang, Multifunctional Cationic Poly(p-phenylene vinylene) Polyelectrolytes for Selective Recognition, Imaging, and Killing of Bacteria over Mammalian Cells, Adv. Mater., 2011, 23, 4805-4810.

16 K.-Y. Pu and B. Liu, Fluorescent Conjugated Polyelectrolytes for Bioimaging, Adv. Funct. Mater., 2011, 21, 3408-3423.

17 B. Kim, I. H. Jung, M. Kang, H.-K. Shim and H. Y. Woo, Cationic Conjugated Polyelectrolytes-Triggered Conformational Change of Molecular Beacon Aptamer for Highly Sensitive and Selective Potassium Ion Detection, J. Am. Chem. Soc., 2012, 134, 3133-3138.

18 Y. Wu, Y. Tan, J. Wu, S. Chen, Y. Z. Chen, X. Zhou, Y. Jiang and C. Tan, Fluorescence Array-Based Sensing of Metal Ions Using Conjugated Polyelectrolytes, ACS Appl. Mater. Interfaces, 2015, 7, 6882-6888.

19 Z. Li, R. Acharya, S. Wang and K. S. Schanze, Photophysics and phosphate fluorescence sensing by poly(phenylene ethynylene) conjugated polyelectrolytes with branched ammonium side groups, J. Mater. Chem. C, 2018, 6, 3722-3730.

20 Y. Tang, F. He, M. Yu, S. Wang, Y. Li and D. Zhu, Radical Scavenging Mediating Reversible Fluorescence Quenching of an Anionic Conjugated Polymer: Highly Sensitive Probe for Antioxidants, Chem. Mater., 2006, 18, 3605-3610.

21 A. H. Malik and P. K. Iyer, Conjugated Polyelectrolyte Based Sensitive Detection and Removal of Antibiotics Tetracycline from Water, ACS Appl. Mater. Interfaces, 2017, 9, 4433-4439.

22 A. S. Tanwar, S. Patidar, S. Ahirwar, S. Dehingia and P. K. Iyer, "Receptor free" inner filter effect based universal sensors for nitroexplosive picric acid using two polyfluorene derivatives in the solution and solid states, Analyst, 2019, 144, 669-676.

23 M. R. Pinto and K. S. Schanze, Amplified fluorescence sensing of protease activity with conjugated polyelectrolytes, Proc. Natl. Acad. Sci. U. S. A., 2004, 101, 7505-7510.

24 F. He, F. Feng, X. Duan, S. Wang, Y. Li and D. Zhu, Selective and Homogeneous Fluorescent DNA Detection by TargetInduced Strand Displacement Using Cationic Conjugated Polyelectrolytes, Anal. Chem., 2008, 80, 2239-2243. 
$25 \mathrm{H}$. Li and G. C. Bazan, Conjugated Oligoelectrolyte/ssDNA Aggregates: Self-Assembled Multicomponent Chromophores for Protein Discrimination, Adv. Mater., 2009, 21, 964-967.

26 Q. Zhou and T. M. Swager, Method for enhancing the sensitivity of fluorescent chemosensors: energy migration in conjugated polymers, J. Am. Chem. Soc., 1995, 117, 7017-7018.

27 Q. Zhou and T. M. Swager, Fluorescent Chemosensors Based on Energy Migration in Conjugated Polymers: The Molecular Wire Approach to Increased Sensitivity, J. Am. Chem. Soc., 1995, 117, 12593-12602.

28 T. M. Swager, The Molecular Wire Approach to Sensory Signal Amplification, Acc. Chem. Res., 1998, 31, 201-207.

29 L. Chen, D. McBranch, H.-L. Wang, R. Helgeson, F. Wudl and D. G. Whitten, Highly sensitive biological and chemical sensors based on reversible fluorescence quenching in a conjugated polymer, Proc. Natl. Acad. Sci. U. S. A., 1999, 22, 12287-12292.

30 C. Y. Tan, M. R. Pinto and K. S. Schanze, Photophysics, aggregation and amplified quenching of a water-soluble poly(phenylene ethynylene), Chem. Commun., 2002, 446-447.

31 J.-M. Koenen, X. Zhu, Z. Pan, F. Feng, J. Yang and K. S. Schanze, Enhanced Fluorescence Properties of Poly(phenylene ethynylene)-Conjugated Polyelectrolytes Designed to Avoid Aggregation, ACS Macro Lett., 2014, 3, 405-409.

32 H. Yue, M. Wu, C. Xue, S. Velayudham, H. Liu and D. H. Waldeck, Evolution in the Supramolecular Complexes between Poly(phenylene ethynylene)-Based Polyelectrolytes and Octadecyltrimethylammonium Bromide as Revealed by Fluorescence Correlation Spectroscopy, J. Phys. Chem. B, 2008, 112, 8218-8226.

33 M. Zhang, P. Wu, W.-T. Dou, H.-H. Han, X.-P. He, C. Tan and Y. Jiang, Conjugated Polyelectrolytes with GalactoseContaining Side Chains for Targeted Hepatoma Cell Imaging, Chem. Commun., 2017, 53, 5625-5628.

34 K. Lee, L. K. Povlich and J. Kim, Label-Free and Self-Signal Amplifying Molecular DNA Sensors Based on Bioconjugated Polyelectrolytes, Adv. Funct. Mater., 2007, 17, 2580-2587.

35 C. Tan, E. Atas, J. G. Muller, M. R. Pinto, V. D. Kleiman and K. S. Schanze, Amplified Quenching of a Conjugated Polyelectrolyte by Cyanine Dyes, J. Am. Chem. Soc., 2004, 126, 13685-13694.

36 H. Huang, F. Shi, Y. Li, L. Niu, Y. Gao, S. M. Shah and X. Su, Water-soluble conjugated polymer-Cu(II) system as a turnon fluorescence probe for label-free detection of glutathione and cysteine in biological fluids, Sens. Actuators, B, 2013, 178, 532-540.

37 X. Zhao and K. S. Schanze, Fluorescent ratiometric sensing of pyrophosphate via induced aggregation of a conjugated, Chem. Commun., 2010, 46, 6075-6077.

38 P. Jagadesan and K. S. Schanze, Poly(phenylene ethynylene) Conjugated Polyelectrolytes Synthesized via Chain-Growth Polymerization, Macromolecules, 2019, 52, 3845-3851.

39 D. Wang, J. Wang, D. Moses, G. C. Bazan and A. Heeger, Photoluminescence Quenching of Conjugated Macromolecules by Bipyridinium Derivatives in Aqueous Media: Charge Dependence, Langmuir, 2001, 17, 1262-1266.
40 H. Jiang, X. Zhao and K. S. Schanze, Effects of Polymer Aggregation and Quencher Size on Amplified Fluorescence Quenching of Conjugated Polyelectrolytes, Langmuir, 2007, 23, 9481-9486.

41 Calculated by the following equations, $\Delta G_{\mathrm{f}}=E\left({ }^{*} \mathrm{CPE} / \mathrm{CPE}^{+}\right)$ $-E\left(\mathrm{~A} / \mathrm{A}^{-}\right)$and $\Delta G_{\mathrm{b}}=\mathrm{E}\left(\mathrm{A} / \mathrm{A}^{-}\right)-\mathrm{E}\left(\mathrm{CPE} / \mathrm{CPE}^{+}\right)$.

42 M. R. Wasielewski, Photoinduced electron transfer in supramolecular systems for artificial photosynthesis, Chem. Rev., 1992, 92, 435-461.

43 Y. Yang, Study on Fluorescence Quenching, Aggregation and Charge Transfer Properties of Conjugated Polymers, PhD Dissertation, University of Florida, 2019.

44 C. R. Bock, J. A. Connor, A. R. Gutierrez, T. J. Meyer, D. G. Whitten, B. P. Sullivan and J. K. Nagle, Estimation of Excited-state Redox Potentials by Electron-transfer Quenching. Application of Electron-transfer Theory to Excited-state Redox Processes, J. Am. Chem. Soc., 1979, 101, 4815-4824.

45 D. Gosztola, M. P. Niemczyk, W. Svec, A. S. Lukas and M. R. Wasielewski, Excited Doublet States of Electrochemically Generated Aromatic Imide and Diimide Radical Anions, J. Phys. Chem. A, 2000, 104, 6545-6551.

46 A. Samanta and G. Saroja, Steady State and Time-resolved Studies on the Redox Behaviour of 1,8-Naphthalimide in the Excited state, J. Photochem. Photobiol., A, 1994, 84, 19-26.

47 J. Peon, X. Tan, J. D. Hoerner, C. Xia, Y. F. Luk and B. Kohler, Excited State Dynamics of Methyl Viologen. Ultrafast Photoreduction in Methanol and Fluorescence in Acetonitrile, J. Phys. Chem. A, 2001, 105, 5768-5777.

48 S. R. Valandro, P. Jagadesan, F. Feng and K. S. Schanze, Aggregation-Enhanced Two-Photon Absorption of Anionic Conjugated Polyelectrolytes, J. Phys. Chem. Lett., 2020, 11, 8292-8296.

49 R. Dillon, Z. Pan, J. Jiang, R. Winkel, J. Papanikolas and K. S. Schanze, Ultrafast Energy Transfer in Fully Conjugated Thiophene-Benzothiadiazole Capped Poly(Phenylene Ethynylene) Molecular Wires, J. Phys. Chem. C, 2020, 124, 18920-18929.

50 A. M. Funston, E. E. Silverman, J. R. Miller and K. S. Schanze, Charge Transfer through Terthiophene EndCapped Poly(arylene ethynylene)s, J. Phys. Chem. B, 2004, 108, 1544-1555.

51 A. O. Patil, A. J. Heeger and F. Wudl, Optical properties of conducting polymers, Chem. Rev., 1988, 88, 183-200.

52 E. M. Kosower and J. L. Cotter, Stable Free Radicals. II. The Reduction of 1-Methyl-4-cyanopyridinium Ion to Methylviologen Cation Radical, J. Am. Chem. Soc., 1964, 86, 5524-5527.

53 C. Thalacker, C. Röger and F. Würthner, Synthesis and Optical and Redox Properties of Core-Substituted Naphthalene Diimide Dyes, J. Org. Chem., 2006, 71, 8098-8105.

54 S. J. Langford, M. J. Latter and C. P. Woodward, Progress in Charge Transfer Systems Utilizing Porphyrin Donors and Simple Aromatic Diimide Acceptor Units, Photochem. Photobiol., 2006, 82, 1530-1540.

55 S. R. Greenfield, W. A. Svec, D. Gosztola and M. R. Wasielewski, Multistep Photochemical Charge Separation in Rod-like 
Molecules Based on Aromatic Imides and Diimides, J. Am. Chem. Soc., 1996, 118, 6767-6777.

56 P. Piotrowiak, Photoinduced Electron Transfer in Molecular Systems: Recent Developments, Chem. Soc. Rev., 1999, 28, 143-150.

57 I. Place, A. Farran, K. Deshayes and P. Piotrowiak, Triplet Energy Transfer through the Walls of Hemicarcerands: Temperature Dependence and the Role of Internal Reorganization Energy, J. Am. Chem. Soc., 1998, 120, 12626-12633.

58 Z. S. Romanova, K. Deshayes and P. Piotrowiak, Triplet Excitation Transfer through the Walls of Hemicarcerands: Depend- ence of the Electronic Coupling on the Size of the Molecular Cage, J. Am. Chem. Soc., 2001, 123, 11029-11036.

59 A. J. Parola, F. Pina, E. Ferreira, M. Maestri and V. Balzani, Photoinduced Electron- and Energy-Transfer Processes of Biacetyl Imprisoned in a Hemicarcerand, J. Am. Chem. Soc., 1996, 118, 11610-11616.

60 A. Das, N. Kamatham, A. M. Raj, P. Sen and V. Ramamurthy, Marcus Relationship Maintained During Ultrafast Electron Transfer Across a Supramolecular Capsular Wall, J. Phys. Chem. A, 2020, 124, 5297-5305.

61 J. Kim, I.-S. Jung, S.-Y. Kim, E. Lee, J.-K. Kang, S. Sakamoto, K. Yamaguchi and K. Kim, New Cucurbituril Homologues: Syntheses, Isolation, Characterization, and X-ray Crystal Structures of Cucurbit $[n]$ uril $(n=5,7$, and 8), J. Am. Chem. Soc., 2000, 122, 540-541.

62 J. W. Lee, S. Samal, N. Selvapalam, H. J. Kim and K. Kim, Cucurbituril Homologues and Derivatives: New Opportunities in Supramolecular Chemistry, Acc. Chem. Res., 2003, 36, 621-630.

63 F. Biedermann, W. M. Nau and H.-J. Schneider, The Hydrophobic Effect Revisited-Studies With Supramolecular Complexes Imply High-Energy Water as a Noncovalent Driving Force, Angew. Chem., Int. Ed., 2014, 53, 11158.

64 H.-J. Kim, W. S. Jeon, Y. H. Ko and K. Kim, Inclusion of Methylviologen in Cucurbit[7] uril, Proc. Natl. Acad. Sci. U. S. A., 2002, 99, 5007-5011.

65 N. S. Sariciftci, L. Smilowitz, A. J. Heeger and F. Wudl, Photoinduced Electron-Transfer from a Conducting Polymer to Buckminsterfullerene, Science, 1992, 258, 1474-1476.
66 G. Yu, J. Gao, J. C. Hummelen, F. Wudl and A. J. Heeger, Polymer Photovoltaic Cells-Enhanced Efficiencies via a Network of Internal Donor-Acceptor Heterojunctions, Science, 1995, 270, 1789-1791.

67 J. M. Hodgkiss, G. Tu, S. Albert-Seifried, W. T. S. Huck and R. H. Friend, Ion-Induced Formation of Charge-Transfer States in Conjugated Polyelectrolytes, J. Am. Chem. Soc., 2009, 131, 8913-8921.

68 A. P.-Z. Clark, A. J. Cadby, C. K.-F. Shen, Y. Rubin and H. Tolbert, Synthesis and Self-Assembly of an Amphiphilic Poly(phenylene ethynylene) Ionomer, J. Phys. Chem. B, 2006, 110, 22088-22096.

69 J. Jiang, A. Alsam, S. Wang, S. M. Aly, Z. Pan, O. F. Mohammed and K. S. Schanze, Effect of Conjugation Length on Photoinduced Charge Transfer in $\pi$-Conjugated Oligomer-Acceptor Dyads, J. Phys. Chem. A, 2017, 121, 4891-4901.

70 J. M. Masnovi, J. K. Kochi, E. F. Hilinski and P. M. Rentzepis, Reactive ion pairs from the charge-transfer excitation of electron donor-acceptor complexes, J. Am. Chem. Soc., 1986, 108, 1126-1135.

71 T. Yabe and J. K. Kochi, Contact ion pairs.Picosecond dynamics of solvent separation, internal return, and special salt effect, J. Am. Chem. Soc., 1992, 114, 4491-4500.

72 E. F. Hilinski, J. M. Masnovi, C. Amatore, J. K. Kochi and P. M. Rentzepis, Charge-transfer excitation of electron donor-acceptor complexes. Direct observation of ion pairs by time-resolved (picosecond) spectroscopy, J. Am. Chem. Soc., 1983, 105, 6167-6168.

73 M. Porel, A. Klimczak, M. Freitag, E. Galoppini and V. Ramamurthy, Photoinduced Electron Transfer Across a Molecular Wall: Coumarin Dyes as Donors and Methyl viologen and $\mathrm{TiO}_{2}$ as Acceptors, Langmuir, 2012, 28, 3355-3359.

74 M. Porel, C.-H. Chuang, C. Burda and V. Ramamurthy, Ultrafast Photoinduced Electron Transfer Between an Incarcerated Donor and a Free Acceptor in Aqueous Solution, J. Am. Chem. Soc., 2012, 134, 14718-14721.

75 C.-H. Chuang, M. Porel, R. Choudhury, C. Burda and V. Ramamurthy, Ultrafast Electron Transfer across a Nanocapsular Wall: Coumarins as Donors, Viologen as Acceptor, and Octa Acid Capsule as the Mediator, J. Phys. Chem. B, 2018, 122, 328-337. 